\title{
Structured Study Abroad Enhances Intercultural Competence
}

Lata A. Krishnan

Purdue University - Main Campus, krishnal@purdue.edu

Christi Masters

Purdue University, mastersc@purdue.edu

Horane Holgate

Purdue University, hholgate@purdue.edu

See next page for additional authors

DOI: doi.org/10.30707/TLCSD1.1Krishnan

Follow this and additional works at: https://ir.library.illinoisstate.edu/tlcsd

Part of the Speech Pathology and Audiology Commons

\author{
Recommended Citation \\ Krishnan, Lata A.; Masters, Christi; Holgate, Horane; Wang, Cong; and Calahan, Charles A. (2017) \\ "Structured Study Abroad Enhances Intercultural Competence," Teaching and Learning in Communication \\ Sciences \& Disorders: Vol. 1: Iss. 1, Article 5. \\ DOI: doi.org/10.30707/TLCSD1.1Krishnan \\ Available at: https://ir.library.illinoisstate.edu/tlcsd/vol1/iss1/5
}

This Scholarship of Teaching and Learning Research is brought to you for free and open access by ISU ReD: Research and eData. It has been accepted for inclusion in Teaching and Learning in Communication Sciences \& Disorders by an authorized editor of ISU ReD: Research and eData. For more information, please contact ISUReD@ilstu.edu. 


\title{
Structured Study Abroad Enhances Intercultural Competence
}

\begin{abstract}
Participation in a service-learning (SL) study abroad (SA) program has been shown to enhance cultural competence (Krishnan, Richards \& Simpson, 2016) as measured via the Public Affairs Scale (PAS; Levesque-Bristol \& Cornelius-White, 2012). The purpose of this study was 1) to evaluate students' development of intercultural competence using the Intercultural Development Inventory (IDI®), a tool specifically designed for this purpose, and 2) to evaluate whether intentionally escalating culturally focused developmental experiential learning together with existing course content would increase cultural competence more than program participation alone. Thirty female and one male student participated over three years of the SL SA program. Quantitative data collected included a pre- and post-program administration of the IDI®. Qualitative data included student reflection papers regarding the intentional cultural intervention activities they completed. Comparison of the pre- and post-IDI® showed mixed results with program participation alone, but showed a significant increase in intercultural competence when intentional cultural interventions were included in course content. Results indicate that a short-term SA program with a SL component can be a mechanism for students to enhance intercultural competence when intentional and targeted cultural interventions are included in course activities.
\end{abstract}

\section{Keywords}

Cultural competence, study abroad, international service-learning

\section{Cover Page Footnote}

Acknowledgements The SLHS in Zambia program was subsidized by Study Abroad and International Learning (SAIL) and International Service-Learning grants from Purdue University each year of the program. We are extremely grateful to all our community-partner organizations in Zambia for allowing us the privilege to work with them and the families that they serve, and to all the children and families that we worked with in Zambia. Many thanks also to K. Andrew R. Richards for feedback on the qualitative data analysis.

\section{Authors}

Lata A. Krishnan, Christi Masters, Horane Holgate, Cong Wang, and Charles A. Calahan

This scholarship of teaching and learning research is available in Teaching and Learning in Communication Sciences \& Disorders: https://ir.library.illinoisstate.edu/tlcsd/vol1/iss1/5 


\section{Introduction}

International service-learning (ISL) is a pedagogical method that combines academic learning and community service in an international context (Crabtree, 2008). It is defined as:

a structured academic experience in another country in which students (a) participate in an organized service activity that addresses identified community needs; (b) learn from direct interaction and cross-cultural dialogue with others; and (c) reflect on the experience to gain further understanding of course content, a deeper understanding of global and intercultural issues, a broader appreciation of the host country and the discipline, and an enhanced sense of their own responsibilities as citizens, locally and globally (Bringle \& Hatcher, 2010, pp. 13-14).

ISL can be conceptualized as an integration of service-learning (SL), study abroad (SA), and international education, and ISL pedagogy draws from the strengths of each of these three domains. SL brings an experiential learning component into ISL, and community service projects provide students with meaningful opportunities to immerse themselves into the host culture. SA brings to ISL the opportunity to provide adequate preparation before, during and after the experience and include developing intercultural competence as a learning objective of the program. International education brings an international perspective into course content and civic education issues (Bringle \& Hatcher, 2010). Combining these aspects, ISL comprises four core components: (1) academic learning, (2) community service, (3) intercultural context, and (4) reflection (Bennett, 2015). Reflection is a crucial element across SL, SA and international education. Effective reflection has been found to help students connect course content with service activities (Deeley, 2010), and deepen students' thinking (Ash, Clayton, \& Atkinson, 2005; Baldwin, Buchanan, \& Rudisill, 2007; Crabtree, 2008). Additionally, reflection journals provide qualitative data that has been used to document and evaluate students' learning outcomes (Evanson \& Zust, 2004; Long, 2014; Krishnan, Richards \& Simpson, 2016).

ISL experiences have been found to promote students' understanding of other cultures and enhance their intercultural competence (Amerson, 2012; Bennett, 2015; Green, Comer, Elliott, \& Neubrander, 2011; Long, 2014; Miller \& Gonzalez, 2009; Caffrey, Neander, Markle \& Stewart, 2005; Krishnan, et al., 2016). Although the findings of studies on ISL and intercultural competence have been promising, most of the ISL research has been conducted in the professions of nursing (Amerson, 2012; Caffrey et al., 2005; Long, 2014; Wilk, 2013), medicine (Godkin \& Savageau, 
2003; Mao, Wax, Barg, Margo, \& Walrath, 2007), and education (Baldwin et al., 2007). Literature related to SL in the professions of audiology and speech-language pathology (SLP) has been limited. The studies that have been conducted report encouraging results relative to graduate (e.g., Cokely \& Thibodeau, 2011; Kaf, Barboa, Fisher, \& Snavely, 2011; Kaf, 2012; Kaf \& Strong, 2011; Pakulski, 2011) and undergraduate student (Peters, 2011) learning through SL. These studies have demonstrated positive educational outcomes of SL consistent with findings of SL research in other areas of higher education (Guo, Yao, Wang, Yan, \& Zong, 2015). Only one study was found that used SL as a tool to facilitate cultural competence in undergraduate students in communication sciences and disorders (Goldberg, 2007). Reports of ISL in the professions of audiology and SLP are even fewer. A few reports have described international programs (e.g. Williams, Louw, Scherer, Bleile, Keske-Soares \& Trindade, 2013; Crowley \& Baigorri, 2011; Crowley \& Baigorri, 2012; McBride \& Belus, 2014), but the only previous study that has examined the influence of ISL on student learning has also evaluated outcomes of the program described in this paper (SLHS in Zambia) and reported increased cultural competence upon program completion (Krishnan, et al., 2016).

There is consensus that there is a need for culturally competent audiologists and SLPs to meet the demands of an increasingly culturally and linguistically diverse client base as evidenced by the knowledge and skills in this area being required by the American Speech-Language-Hearing Association (ASHA). It is widely accepted that intercultural competence involves the development of intercultural knowledge, attitudes and skills related to awareness of one's own culture and other cultures, as well as valuing and understanding of cultural differences (Deardorff, 2006). SA experiences are one way that students can develop intercultural competence (Vande Berg, Connor-Linton, \& Paige, 2009). However, it has been suggested that merely immersing students into the host culture does not guarantee that students will develop intercultural competence. Developing intercultural competence through SA experiences requires intentional and targeted interventions that allow students to reflect on their experiences as they engage with cultural differences (Berg, Paige \& Lou, 2012).

The Intercultural Development Inventory (IDI®) is one of the most widely used measures of intercultural competence and cross-cultural sensitivity in research across various disciplines and professional practices (Hammer, 2015). It is cited as one of the most robust and valid measures of intercultural competence and is especially suited for assessing intercultural development through SA experiences (Anderson \& Lawton, 2011; Hammer, 2011; Paige, Cohen \& Shively, 2004). The IDI ${ }^{\circledR}$ has a strong theoretical foundation, based on the Intercultural Development Continuum (IDC) which was developed from Bennett's (1986, 1993) Developmental Model of Intercultural Sensitivity (DMIS). The DMIS is based on 
the premise that intercultural competence develops along a continuum from the more monocultural or ethnocentric mindsets of Denial and Polarization to the more global, ethnorelative or intercultural mindsets of Acceptance and Adaptation. The framework also includes a transitional orientation between the ethnocentric and ethnorelative orientations that is referred to as Minimization (e.g. Hammer, 2011). The IDI ${ }^{\circledR}$ has been shown to approximate the DMIS and has a low social desirability bias (Paige, Jacobs-Cassutob, Yershovaa \& DeJaegherea, 2003). Several studies using quantitative and qualitative methodologies or a combination of both have documented students' development of cross-cultural competence and sensitivity based on engagement in short-term ( 5 weeks or less) (Anderson, Lawton, Rexeisen \& Hubbard, 2006; Czerwionka, Artamonova \& Barbosa, 2015; Jackson, 2008, 2009, 2011; Lo-Philip \& Park, 2015) and longer term (semester to yearlong) (Anderson \& Lawton, 2011; Paige, et al., 2008; Pedersen, 2009, 2010; Rexeisen, Anderson, Lawton \& Hubbard, 2008) SA experiences.

Based on the benefits of ISL in other professions, and the limited evidence related to SL and ISL in the professions of audiology and SLP, the purpose of this study was twofold: 1) to expand on previous findings (Krishnan, et al., 2016) by evaluating students' development of intercultural competence using the IDI ${ }^{\circledR}$, and 2) to evaluate whether intentionally escalating culturally focused developmental experiential learning together with existing course content would increase cultural competence more than program participation alone.

\section{Method}

SLHS in Zambia ISL Program. The SLHS in Zambia program was developed in 2011-2012 based on a partnership between the Department of Speech, Language, and Hearing Sciences (SLHS) at a large University and the only audiologist working in Zambia. Although there is University support for SA and SL programs via the Study Abroad Office, the Office of Engagement, and the SL faculty grant program through the Center for Instructional Excellence (CIE), most SA programs are developed and administered by faculty in their individual departments. Two clinical faculty members in Audiology led the inaugural program in 2013. From 2014 to 2016, the program was broadened to include speech-language activities and was led by one clinical faculty member in audiology and one in SLP (first and second authors).

The goals of the program were for students to increase their intercultural competence, improve their clinical skills by participating in hearing screenings and speech-language consultations, participate in professional development trainings, and think critically about global challenges in healthcare. The program included four components: 
1) Spring semester: 8-10 weekly class sessions

2) Summer session: one week of intensive daily classes and lab activities focused on practicing skills related to hearing screenings and training presentations

3) Summer session: two weeks of program activities in Zambia working at multiple sites with different community partner organizations, and nightly reflections and de-briefings

4) Summer session: final debriefing meeting upon return from Zambia

The first component during the spring semester focused on gaining knowledge about Zambia (all participants) and on culturally focused intervention activities (experimental groups, E1 [2015] and E2 [2016]). Class activities and assignments included a book discussion; papers and presentations on 1) the history, geography, government, economy, healthcare system, education system, culture and wildlife in Zambia; 2) more common medical conditions students were likely to encounter including malaria, clubfoot, hydrocephalus and HIV/AIDS; and 3) each of the community partner organizations in Zambia. During this time, each student was partnered with a student majoring in Special Education at the University of Zambia (UNZA) and began corresponding via e-mail with their partner who they later met in Zambia.

The second component in the first week of the summer session included daily instruction focused on having students learn and practice clinical skills to perform hearing screenings. During this time students also practiced their training presentations on the topics of Hearing Screening, Augmentative and Alternative Communication (AAC), and Speech and Language Development (typical development and strategies to facilitate language development in children with the hearing loss). These training topics were selected at the request of Zambian professionals at some of the community partner organizations.

The third component took place in Zambia where the students participated in daily scheduled activities at various community partner organizations including a nonprofit hospital, two non-profit organizations that serve children with disabilities, an orphanage, a primary school, a center for children at risk for HIV/AIDS including their early intervention clinic, and UNZA. An important aspect of these two weeks was the nightly debriefing sessions where students reflected on the day's activities and shared their observations and feelings. The program was limited to two weeks in Zambia due to the University summer session duration of four weeks, to allow one week for preparation and return / debriefing respectively, and to allow graduate 
students to participate in the program without impacting their summer courses and clinical placements. The last component of the program upon return from Zambia included a final debriefing session where students led the discussions and faculty facilitated their reflections encompassing the entire program.

Participants. A total of 30 female and one male student participated in the program over the course of three years. As with most programs in speech-language and hearing across the US, there are very few male students in the program, and no male students applied for the program in 2014 and 2016.

2014 (Control group). Twelve female students participated in the program and formed the control group. The participants included ten undergraduate students majoring in SLHS and two graduate students. There was one freshman, one sophomore, eight juniors, and two students in the second year of the clinical Doctor of Audiology (AuD) program. The average age of the participants was 21.08 years $(\mathrm{SD}=1.51)$. All twelve students were Caucasian.

2015 (Group E1). Nine students participated in the first experimental group: eight were female and one was male. They included six undergraduate students who were all juniors and three graduate students who were first year AuD students. The average age of the participants was 21.78 years $(S D=1.2)$. Eight students were Caucasian and one was Asian-American.

2016 (Group E2). Ten female students participated in the second experimental group including seven undergraduate students (six juniors and one sophomore) and three graduate students who were all second year AuD students. The average age of the participants was 22.1 years $(S D=1.6)$ and all ten students were Caucasian.

Research Procedures and Data Collection. Human subjects approval through the university Institutional Review Board (IRB) was obtained to use the data gathered as part of the course requirements. At the conclusion of the program and after all student records had been de-identified, the course instructors partnered with researchers from the CIE who had no background in audiology or SLP to analyze the data and interpret results. One researcher (the last author) is a qualified administrator of the IDI ${ }^{\circledR}$ and contributed to course content in intercultural competency development using the IDI®.

Both quantitative and extensive qualitative data were collected from the participants; this paper discusses the following portions of the data: 1) pre- and post-program administration of the IDI® (Hammer, Bennett \& Wiseman, 2003) to measure changes in participants' intercultural competence through program participation and 2) student reflection papers regarding the intentional cultural 
intervention activities they completed as part of the course requirements. More detailed qualitative data analyses from the inaugural year of the program have been published previously (Krishnan, et al., 2016).

Intercultural Development Inventory (IDI®). All participants completed the IDI® online. The IDI® is a 50-item questionnaire that uses a five-point, Likert-type scale ranging from disagree (1) to agree (5). Example questions include: "It is appropriate that people do not socialize very much with individuals from different cultures" and "Despite some cultural differences, it is important to recognize that people are all alike in their humanity".

The IDI@ is based on the developmental model of intercultural sensitivity (Bennett, 1986) and was administered and scored by a qualified administrator. Individual and group Developmental Orientation (DO) scores obtained using the IDI ${ }^{\circledR}$ are reported. After administration of the IDI ${ }^{\circ}$, individual and group profile reports were generated as well as an individually customized Intercultural Development Plans (IDP®) for each participant. The IDP® provides suggestions for specific activities to develop intercultural competence.

Control group participants completed the IDI ${ }^{\circledR}$ two to three months prior to departing for Zambia and immediately after the conclusion of the program, but did not receive an IDP® or any specific cultural interventions other than participating in the SA program. In addition to completing the pre- and post-program IDI@, the experimental groups' participants completed several additional IDI ${ }^{\circ}$ activities including 1) a video presentation and discussion regarding the IDI $®$ continuum; 2) individual meetings with the IDI ${ }^{\circledR}$ administrator to discuss their scores and receive their customized IDP®; 3) completion of two (Group E1 participants) or three (Group E2 participants) activities suggested in their IDP® and 4) written paper reflecting on what new information was most meaningful to them after completing these activities and how the new information might change their perceptions, interpretations, judgments, reactions and/or behaviors in the future. Furthermore, cultural intervention activities were presented in a more focused manner for Group E2, and participants were encouraged to complete as much of their personalized IDP ${ }^{\circledR}$ as possible and reflect on their experiences using the Describe-InterpretEvaluate (D.I.E.) model (Bennett, Bennett \& Stillings, 1977) to raise their awareness of cultural learning strategies.

Cultural Intervention Activities. Control group participants read the book The Boy Who Harnessed the Wind (Kamkwamba \& Mealer, 2009), wrote a book report and had a book discussion in class. They also practiced greetings in the local language of Nyanja in class. There were no specific or focused cultural intervention 
activities planned within the course content. However, students wrote daily journals during their time in Zambia as well as a final reflection paper.

In addition to these activities, both experimental groups' participants were involved in several in-class intentional cultural intervention activities throughout the spring semester. These activities included 1) a "challenging assumptions" exercise: an exercise exploring assumptions about others based on appearance ("Cultural Self Awareness", 2009); 2) a discussion of cultural differences between the USA and other cultures using the iceberg concept of culture (Hall, 1976), which proposes that cultural differences commonly observed, such as differences in food, dress, music etc. represent surface culture, while the majority of more important cultural differences are not easily observed (deep culture); 3) a multi-perspective cultural identity activity (Griffer \& Perlis, 2007) where participants had to describe their cultural perspectives and share one example of how their perspective has been shaped ; 4) attending a talk entitled "Student Learning Abroad: What our students are learning, what they are not, and what we can do about it" by Dr. Michael Vande Berg, an instructor for the IDI® qualifying seminar, where he discussed crossing cultural boundaries (Group E1 only); 5) discussion of "current events" in Zambia after reading selected online news articles (Group E1 only); and 6) attendance at and discussion regarding the African Student Association Night. Course content for each year of the program is summarized in Table 1.

Data Analysis. Paired sample t-tests and an analysis of variance (ANOVA) were used to compare the mean pre- and post-DO scores for the participants in each year of the program. Preliminary data screening revealed that the data were skewed due to one significant outlier in the control group (see Figure 1) and one possible outlier in group E1 (see Figure 3). The data for these two groups were analyzed both with and without the outlier, and the results were significant with either analysis. Additionally, a simple linear regression was performed to determine whether the pre-DO scores predicted the difference in the gains in intercultural competence seen between the two experimental groups.

Qualitative data collected from participant papers were analyzed by the first two authors. The first phase of analysis involved open and axial coding (Glaser \& Strauss, 1967), during which the researchers read through multiple transcripts individually, wrote research memos, and identified emerging patterns in the data. These memos were discussed during meetings after which the researchers independently coded additional transcripts and began to formulate coding categories. These categories were developed into a codebook during subsequent research meetings, and used to code data in the second phase of analysis. 
Table 1: Course activities for the three groups of participants. Note: 5 of 9 students from Group E1 and 9 of 10 students from Group E2 attended the African Student Association Night activity

\begin{tabular}{|c|c|c|c|}
\hline Activities & $\begin{array}{l}\text { Control } \\
(\mathrm{n}=12)\end{array}$ & $\begin{array}{l}\text { Group } \\
\text { E1 }(n=9)\end{array}$ & $\begin{array}{l}\text { Group } \\
\text { E2 } \\
(\mathrm{n}=10)\end{array}$ \\
\hline Spring semester classes & $X$ & $X$ & $X$ \\
\hline Learning about Zambia & $X$ & $X$ & $X$ \\
\hline Book reading (The Boy who & & & \\
\hline Harnessed the Wind) & $X$ & $X$ & $X$ \\
\hline Local language (Nyanja) practice & $\mathrm{X}$ & $X$ & $X$ \\
\hline $\begin{array}{l}\text { Focused discussion re: reflecting } \\
\text { and journaling using D.I.E. }\end{array}$ & - & - & $\mathrm{X}$ \\
\hline Daily journals & $\mathrm{X}$ & $X$ & $X$ \\
\hline Nightly de-briefing in Zambia & $X$ & $X$ & $X$ \\
\hline Final reflection papers & $X$ & $X$ & $X$ \\
\hline \multicolumn{4}{|l|}{$\begin{array}{lll}\text { Focused cultural intervention } \\
\text { activities }\end{array}$} \\
\hline Challenging assumptions exercise & - & $\mathrm{X}$ & $\mathrm{X}$ \\
\hline Iceberg concept of culture & - & $X$ & $X$ \\
\hline $\begin{array}{l}\text { Multi-perspective cultural identity } \\
\text { exercise }\end{array}$ & - & $X$ & $\mathrm{X}$ \\
\hline Student Learning Abroad talk & - & $X$ & - \\
\hline $\begin{array}{l}\text { Current events in Zambia } \\
\text { discussion }\end{array}$ & - & $\mathrm{X}$ & - \\
\hline African Student Association Night & - & $\mathrm{n}=5$ & $\mathrm{n}=9$ \\
\hline \multicolumn{4}{|l|}{ IDI® activities } \\
\hline Pre- and post-IDI® & $\mathrm{X}$ & $X$ & $\mathrm{X}$ \\
\hline IDI@ video presentation & - & $X$ & $X$ \\
\hline $\begin{array}{l}\text { Individual debrief with IDI® } \\
\text { administrator and receipt of IDP® }\end{array}$ & - & $X$ & $X$ \\
\hline Required IDP® activities & - & 2 & 3 \\
\hline IDP® reflection paper & - & $X$ & $\mathrm{X}$ \\
\hline
\end{tabular}


During the second phase of analysis, the researchers used a combination of inductive analysis and the constant comparative method (Patton, 2002). Through inductive analysis, they independently coded the entire dataset and met to discuss the coding process. They then discussed each individually coded participant quotation along with the emerging theme into which they had coded the quotations. When classification disagreements occurred, the researchers discussed the item and came to agreement on the coding decision. Constant comparison (Glaser \& Strauss, 1967; Patton, 2002) was used as the researchers made modifications to the codebook based on newly coded data. After all of the data had been coded, the researchers reviewed the coding structure, made modifications, and finalized the themes.

Trustworthiness of the qualitative data analysis process was enhanced through researcher triangulation and an audit trail (Lincoln \& Guba, 1985). Research triangulation was achieved through the use of two coders in the qualitative data analysis process. An audit trail was constructed by cataloging all steps involved in the data analysis process. This audit trail helped maintain transparency by documenting the progress made toward completion of the analyses.

\section{Results}

The purpose of this study was to assess participants' intercultural competence prior to and at the conclusion of a two-week SL SA program and determine whether focused cultural intervention activities embedded in the course content led to better outcomes compared to program participation alone. Overall the results of the study are positive indicating that although program participation alone may lead to positive outcomes for some participants, the addition of cultural intervention activities improves outcomes for the group. Quantitative results will be presented for the IDI ${ }^{\circledR}$ followed by qualitative data regarding student perceptions of the cultural activities they completed as part of their IDP®.

Quantitative Data. IDI®. Descriptive statistics and paired sample t-test results for the DO scores are shown in Table 2.

Group mean DO scores for all three groups are displayed in Figure 1. For the control group, there was no significant change in the group mean DO score from pre- (94.2) to post-program (94.3). A significant increase in the group mean DO score was seen in both the experimental groups: for Group E1, the mean DO score increased from 83.7 to 97.7 (14 points), while for Group E2, the mean score increased from 96.8 to 107.6 (10.8 points). 
Teaching and Learning in Communication Sciences \& Disorders, Vol. 1 [2017], Iss. 1, Art. 5

Table 2. IDI@ descriptive statistics and paired sample t-tests for each group.

\begin{tabular}{|c|c|c|c|c|c|c|c|c|c|c|c|}
\hline & Pretest & & Post-tes & & & & & & & & \\
\hline Group & M & SD & M & SD & $\mathrm{n}$ & $\begin{array}{l}\text { Mean } \\
\text { Difference }\end{array}$ & $\begin{array}{l}95 \% \text { CI for } \\
\text { Mean } \\
\text { Difference }\end{array}$ & $\mathrm{r}$ & $\mathrm{t}$ & df & Sig. \\
\hline $\mathrm{C}^{\mathrm{a}}$ & 94.17 & 9.77 & 94.25 & 13.61 & 12 & -0.083 & $-10.85,10.69$ & .03 & $\overline{-}-02$ & 11 & .987 \\
\hline$C^{b}$ & 94.73 & 10.04 & 91.18 & 8.92 & 11 & 3.56 & $-4.16,11.56$ & .21 & 0.99 & 10 & .347 \\
\hline E1 & 83.67 & 10.27 & 97.67 & 11.86 & 9 & -14.00 & $-21.21,-6.79$ & .65 & $\overline{4}-48$ & 8 & $\begin{array}{l}.002 * \\
*\end{array}$ \\
\hline $\mathrm{E} 2^{\mathrm{a}}$ & 96.80 & 12.39 & 107.57 & 12.57 & 10 & -10.76 & $-19.26,-2.26$ & .55 & $\begin{array}{l}- \\
2.87\end{array}$ & 9 & $.019 *$ \\
\hline$E 2^{\mathbf{b}}$ & 93.76 & 8.28 & 106.86 & 13.13 & 9 & -13.10 & $-20.68,-5.53$ & .66 & - & 8 & $\begin{array}{l}.004 * \\
* \\
\end{array}$ \\
\hline
\end{tabular}

$\mathrm{C}=$ control group $\mathrm{E}=$ experimental group; ${ }^{\mathbf{a}}=$ with outlier; $^{\mathbf{b}}=$ without outlier; $*=\mathrm{p}<.05 ; * *=\mathrm{p}<.01$.

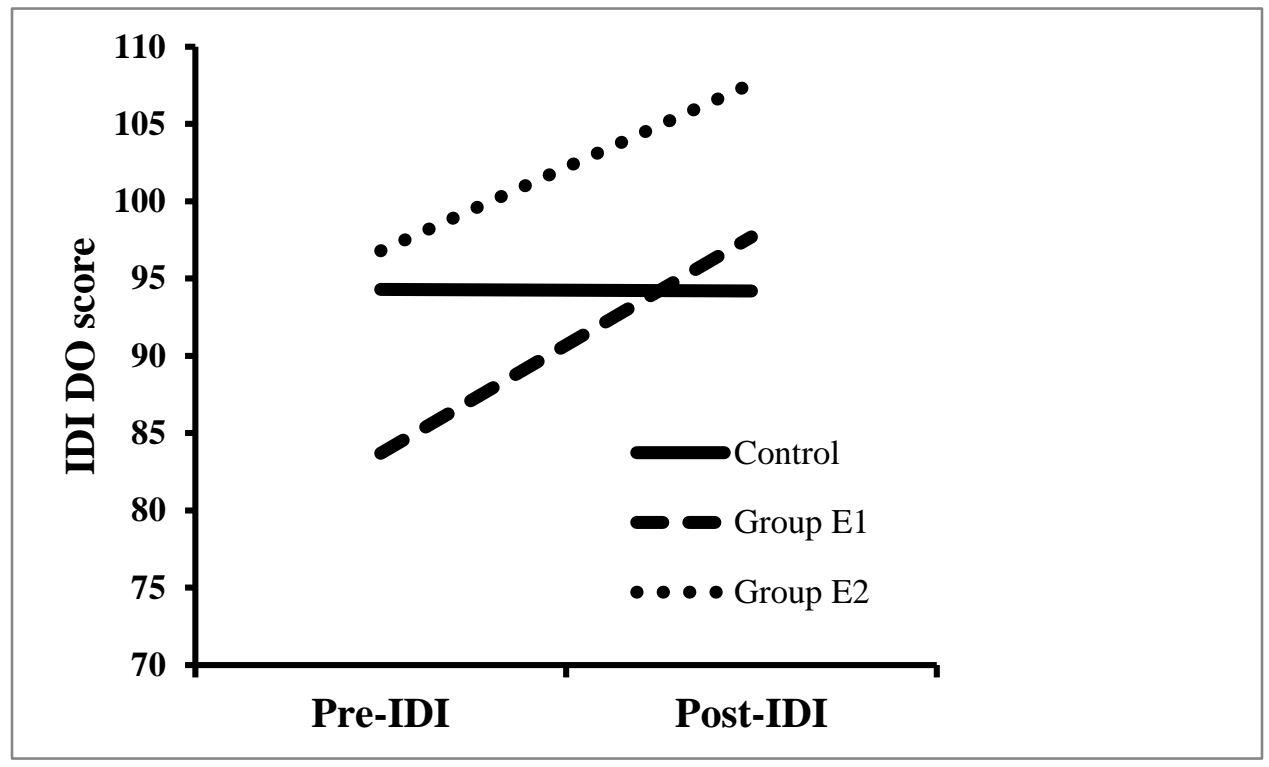

Figure 1: Pre- and post-program group mean DO scores for the three groups of participants 
Figures 2, 3, and 4 show the individual participant data for each of the three groups. Although the group mean DO score did not change post-program for the control group, changes in post-program DO scores were observed for individual participants, with five of the 12 participants showing an increase, and the remaining seven showing a decrease in their DO scores post-program. In the experimental groups, all nine participants in Group E1 showed an increase in their post-program DO scores and nine of 10 students in Group E2 showed an increase.

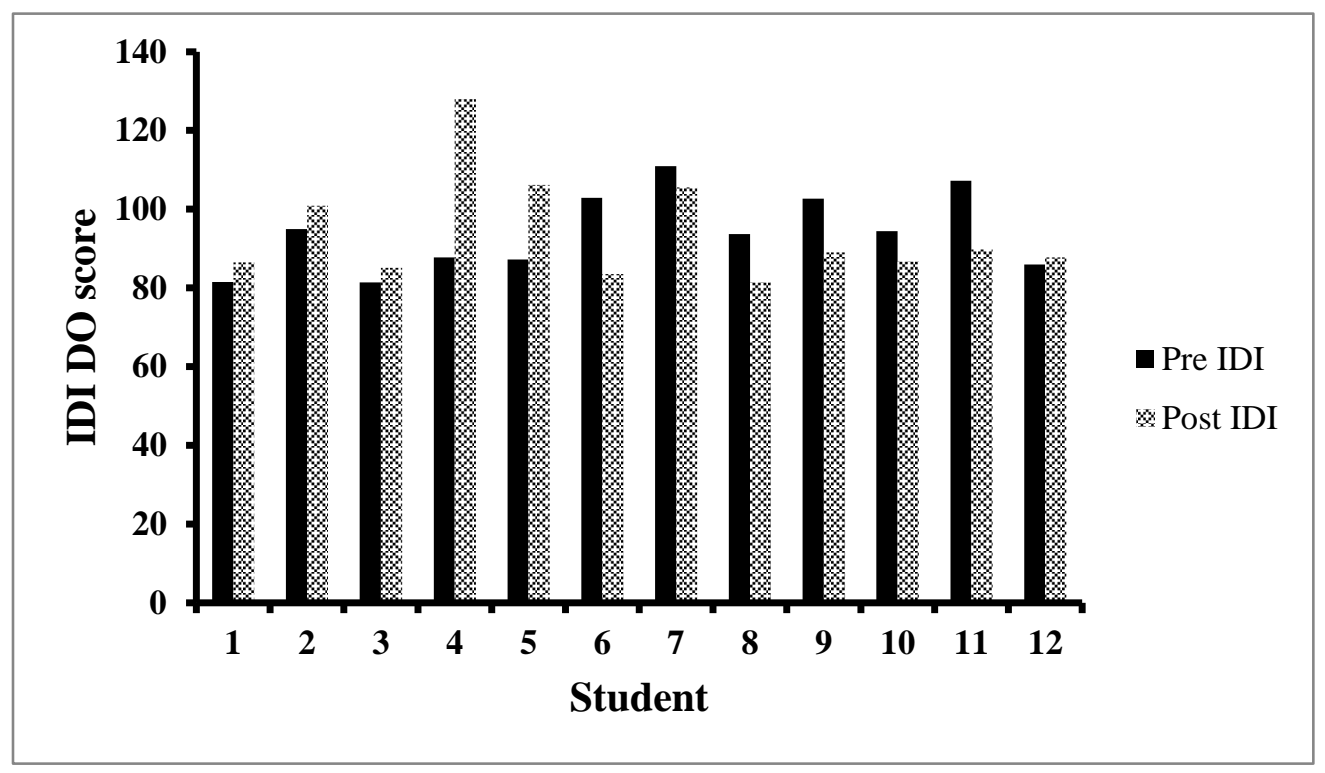

Figure 2: Pre- and post-program DO scores for 12 participants in the control group 


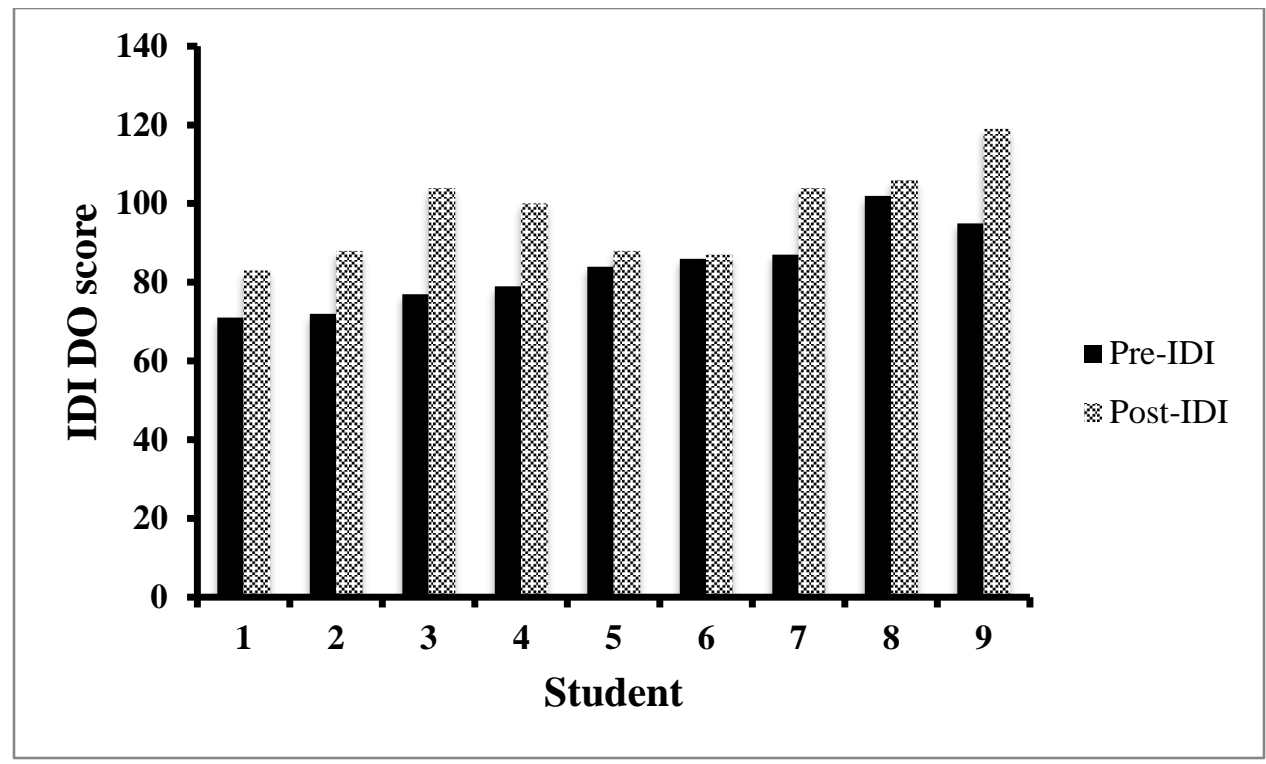

Figure 3: Pre- and post-program DO scores for nine participants in the Group E1

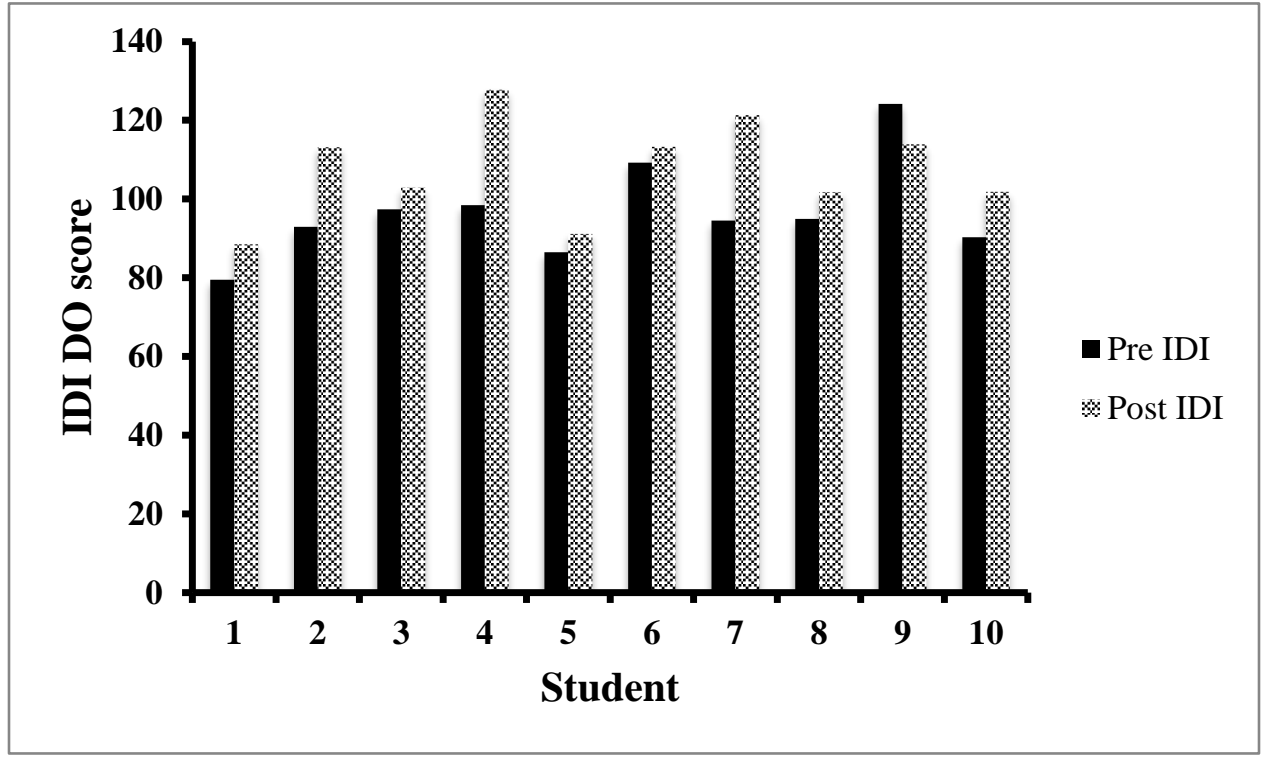

Figure 4. Pre- and post-program DO scores for 10 participants in Group E2

A secondary research question that emerged during data analysis was whether the group mean increase in intercultural competence development observed was based on the pre-program DO score. This question warranted further examination because Group E1 started at a lower pre-program DO score representing a monocultural 
mindset in the polarization category $(M=83.67, S D=10.27)$ than both Group E2 $(M=96.80, S D=12.39)$ and the control group $(M=94.14, S D=13.61)$ whose preprogram DO scores were in the transitional minimization category. The results of the simple linear regression indicated a negative relationship between the preprogram DO scores and the difference between pre-post DO scores that was statistically significant $\left(\mathrm{R}^{2}=.25 F(1,28)=9.07, p=0.005\right)$. Twenty-five percent of the variance in the difference from pre- to post-DO score was explained by the preDO score indicating that the degree of change in intercultural competence can be influenced by the pre-program DO score $(\beta=-.55, \mathrm{p}<.01)$.

In order to determine whether there were significant differences between the three groups based on the difference in DO scores, a one-way ANOVA was performed (excluding the outlier who showed a 40-point increase in DO score in the control group). Results revealed statistically significant differences between the groups $F$ $(2,27)=7.15 p=.003$. Post-hoc comparisons using the Tukey HSD showed that the control group $(M=-3.55, S D=11.93)$ was significantly different than Group E1 $(M=14.00, S D=9.38)$ and Group E2 $(M=10.76, S D=11.88) p<.05$. There was no significant difference between the two experimental groups E1 and E2.

Qualitative Data. Table 3 summarizes the activities completed by the two experimental groups as part of their personalized Intercultural Development Plan (IDP®); the control group did not complete these activities.

All participants also wrote a reflection paper after completion of the activities. Quotations from the dataset will be presented, and the participant associated with each quotation is identified using a pseudonym. There were many general positive comments about completing the activities such as "This was definitely something I am glad I did and it really helped me open my eyes to our future trip" (Lisa, E1), and "I very much enjoyed all three activities and believe I have learned much from them.... I cannot wait to put these new ideas into action when we visit Zambia in a little less than a month" (Hilary, E2). The large majority of participants' comments (73\% of coded comments) were related to Learning, including learning about a different culture, as well as, learning about themselves. Overall, participant comments were categorized into two primary themes: Learning (104 comments) and Emotional Experiences (39 comments). 
Table 3. IDP® activities completed by students

\begin{tabular}{lll} 
IDP® Activity & $\begin{array}{l}\text { Group } \\
\text { n }\end{array}$ & $\begin{array}{l}\text { Group E2 } \\
\text { n }\end{array}$ \\
\hline African Student Association Night & 5 & 9 \\
Read article to highlight differences in culture & 4 & 5 \\
Identify and compare cultural perceptions and characteristics & 1 & 0 \\
"Making Sense of Values" & 2 & 0 \\
Interact with someone from a different culture & 4 & 5 \\
List situations where I minimize my own cultural experiences & 1 & 0 \\
Review M.R. Hammer's Intercultural conflicts style model & 1 & 0 \\
Documentary "Stealing Africa" & 0 & 10 \\
Read book "Yes Chef" & 0 & 1 \\
\hline $\begin{array}{l}\text { Note: } n \text { = number of participants who completed the activity. Two activities were required for Group } \\
\text { E1, three for Group E2, and none for the control group. }\end{array}$
\end{tabular}

Theme One: Learning. All 19 students commented on learning from having completed the IDP® activities, and most comments were specific to learning about culture or about themselves. For example, Kitty (E1) commented on how she examined ways that she minimized her own culture, and realized "that if everyone minimizes, we are missing out on the richness of the diversity around us. It is not always the best strategy to use if you wish to be more culturally competent". Jenny (E1), added:

Learning from both these activities, I can change my perspective and judgments for the future. One perspective I can take on is that even though there are different individuals in a country - there will always be a commonality between them and that they are still aware of their own cultures and roots. This information will help me in the future, because I will acknowledge the differences between individuals and not assume that everyone from a certain country is the same. 
One of the primary goals of the SLHS in Zambia program was to increase participants' intercultural competence. Participants shared general comments such as a growing "appreciation for African culture" (Kim, E1) and becoming "more aware of my thoughts toward other cultures, my own values, and myself" (Gail, E1). Gail also added "Instead of seeing things as black and white, right and wrong, I need to see things as a myriad of color in which to learn and experience life."

Many participants commented specifically that they learned about "African time" by attending the African Student Association Night. For example Linda (E2) said "something that was apparent was that the importance of time for them is different from ours". Kitty (E1) expanded on this with "African time is a real thing that I need to be aware of and adapt to when I am among the culture". Louisa (E2) summarized her thoughts on "African time" saying:

...realizing that my perception of time is not the correct perception, but simply a different one, will help me to be more understanding in the future. Instead of thinking someone is rude by showing up late, hopefully I will be able to think that it may be due to a cultural difference.

Group E2 participants all watched the documentary Stealing Africa from which they learned more about poverty. Greta (E2) said: "my perceptions have changed in how I view poverty" and she "learned to not judge unemployed or poor people and assume the worst of an individual". Martha (E2) added:

...changed my views on poverty in developing nations because we never know what exactly is going on there. My perspective of poverty stricken nations used to be that they just didn't have anything going for them. However, Zambia has so much wealth in their land. It is an injustice that the Zambian people are suffering this much when there is so much potential for success in their nation.

Many participants made comments that centered on the similarities and differences in culture that they noticed. Comments included "though there were some similarities, the differences are the ones that really made me think about and even change some of my perceptions" (Harriet, E2) and "...we may have a different skin tone and live in a different part of the world, but we still share many values" (Taylor, E1). Gail (E1) added:

By focusing on the similarities and the values we shared, I was able to see other cultures in a way I had never even thought to look for. I tend to run away from differences, but focusing on the similarities allowed me to see 
beyond the difference and accept that these people are not so different after all.

Martha (E2) summed up this sentiment with:

I have learned that all cultures do have similarities and differences on the surface but the core of culture is more than these similarities and differences. Evaluating [my buddy's] responses has allowed me to think deeper as to what my own stereotypes are towards cultures and why I have felt this way.

Many participants discussed how their perspective changed after completing the activities and how they would interact differently with someone from another culture. An example of this is Bobbie's (E2) comment that "the best policy when in contact with another cultural group is to keep an open mind, respect differences, and reflect and learn from these unique experiences". Lisa (E1) stated that she would "have a more positive outlook towards differences with other cultures" and that the activities "helped open my eyes and gave me a better grasp on what to think I should expect for our travels to Zambia".

Gail's (E1) perspective changed when she reflected on a time that she experienced a negative reaction with a person from another culture:

This was extremely helpful and allowed me to understand the situation better. I may have seen their actions as disrespectful, but they, in not sharing my values, did not think anything of it. I was able to see their point of view, which relieved some of the hurt or negative feelings I had experienced in that moment.

Participants also discussed an increase in self-awareness, such as Kristin (E1) who stated she learned "to listen carefully and not jump to conclusions of what is right and wrong", that the "underlying causes of actions and ideas are instilled in us by our culture" and to "continually remind myself that differences does not always equal bad". Taylor (E1) summed up his changed perspective with:

I plan on looking at the bigger picture when I meet someone who has a different culture than mine. Instead of focusing on things that are different in a negative light, I want to celebrate the similarities and differences that we share. If I am able to accomplish this feat, I hope to gain a further understanding of many cultures. This in turn will...allow me to take the most out of the interaction or friendship. 
This increased self-awareness led some participants to acknowledge that they previously passed judgments on others from a different culture due to differences, and that they would avoid that going forward, such as Gail (E1) who said:

This taught me to stop before my emotions cloud my judgment and think about the differences in culture and to appreciate these differences. It also made me aware of my need for humility in approaching a person from another culture. I need to not think that my way is the only way, but that sometimes there is no right answer.

Hilary (E2) added:

I think it teaches me Zambia is in a much different place than America is and I should not pass judgment on their standard of living by comparing it to ours, even though this is my first instinct. It teaches me that I should evaluate the different struggles Zambia faces and interpret their way of life based on these facts.

Louisa (E2) summarized with this comment:

After completing these three tasks, I feel more aware of areas I am more likely to be judgmental...I can now take what I have learned and simply choose to see a difference. I have and will continue to learn that a difference is simply just a difference, and the most important thing is to maintain a general respect for everyone.

Theme Two: Emotional experiences. The second theme that emerged from the qualitative analysis was emotional experiences (27\% of coded items). Many participants commented on both emotional challenges such as uneasiness, sadness and feeling disheartened as well as positive emotions, such as, feeling inspired, motivated and eager. The majority of the comments categorized as emotional challenges resulted from participation in the African Student Association Night, where participants were in the minority and felt uncomfortable. Examples of such comments include "I have learned how uncomfortable it is to walk into a room when you are a minority" (Martha, E2), and "it would be a lie to say that I wasn't a little uncomfortable in this setting (Barbara, E2). Kim (E1) expanded on this with:

I felt out of my comfort zone because I have never been the racial minority of a group. I noticed that I was resistant to participate in some of the activities, which I believe resulted from social uneasiness in a new situation. 
Some participants reported the uneasiness came from feeling like they had "no idea what was going on at times" (Barbara, E2) and that other people in attendance must be "wondering what I was doing there" (Martha, E2). Greta (E2) "learned how isolated and alone I can feel when I do not 'look' like everyone else in the room". Taylor (E1) acknowledged his fears with "I think that some cultural boundaries scare me, and because of that I have not interacted with very many people outside of my cultural community".

Participants expressed sadness when comparing healthcare between the United States and Zambia, with comments such as "many of the illnesses in this povertystricken country cannot be treated because of the poor healthcare system" (Greta, E2) and "Africans are suffering every day of illnesses that are easily treatable in the United States" (Barbara, E2).

Although participants felt emotional challenges, most of them also expressed positive emotions, even relative to the African Student Association Night. Wilma (E2) said the activities were "inspiring" and "eye opening" and that the "night showed how much pride they [African students] take in their culture, which is very motivational". Jane (E1) added that she was "eager to see how my attitude and view may change after experiencing another culture for an extended amount of time, instead of just glimpsing a taste of culture", while Louisa (E2) said "... after about 20 minutes of accepting that it was going to be different, I was able to let go and enjoy myself."

Overall, participants also felt positive about completing the activities with comments such as "I think these activities were all very eye opening" (Wilma, E2), "I thought each activity was meaningful" and "I feel like I learned a lot" (Linda, E2).

\section{Discussion}

The primary aim of this study was to evaluate whether adding intentional culturally focused developmental experiential learning into course content in a short-term international SL program would increase cultural competence to a greater extent than program participation alone. Overall, the findings of this study indicate that the cultural intervention activities were effective and led to a significant increase in intercultural competence compared to program participation alone. Qualitative data analyses complemented these findings as the large majority (73\%) of participant comments discussed cultural learning and personal growth.

Focused cultural intervention. It has been previously argued that mere participation in a SA program does not inherently lead to increased intercultural 
competence; rather course content has to include culturally focused content in order to demonstrate development of intercultural competence (Berg et al., 2012). Support for this notion comes from previous studies that used the IDI ${ }^{\circledR}$ and showed no change in group mean DO scores after participation in a SA program with no cultural intervention (Medina-Lopez-Portillo, 2004). Other studies with no cultural intervention have shown modest score changes of 3-5 points on post-program DO scores that were marginally significant (Anderson \& Lawton, 2011; Rexeisen et al., 2008). In all these studies, individual participant data when reported showed that some participants had gains in their scores while others declined; with a net result of little or no change in group mean scores. The results of the current study provide further support to the idea that participation in a SA program alone may not improve intercultural competence, as participants in the control group who received no focused cultural intervention showed no change in group mean scores, although several individual participants' scores increased while others declined.

Studies that have included a cultural training component have utilized a variety of pedagogical methods for the training and had varied results ranging from no change in group scores (Engle \& Engle, 2004), to modest increases of 2-4 points (Anderson et al., 2006; Jackson, 2011; Paige, et al., 2004; Pedersen, 2009), to large changes in scores ranging from 12-25 points (Pedersen, 2009, 2010; Jackson, 2008). These large score changes were subsequent to three months of pre-program preparation including pre-trip seminars on intercultural communication, cultural studies during the SA program, post-trip debriefing (Jackson, 2008), individual coaching and class activities based on the DMIS (Pedersen, 2009, 2010). Again, where individual participant data was included, while many participants demonstrated increases in their scores, 14-31\% of participants declined (Anderson et al., 2006; Jackson, 2008, 2011; Engle \& Engle, 2004). The results of the current study support the notion that focused cultural intervention activities lead to greater increased intercultural development than just participating in a SA program. Specifically, a variety of inclass activities aimed at raising self-awareness and awareness of cultural differences, understanding of the DMIS, participation in focused cultural activities based on the IDP®, and reflection using the D.I.E. model (Bennett, et al., 1977) were effective. Additionally, different from previous studies, across the two experimental groups in this study, all but one of the 19 participants (95\%) showed an increase in their DO score. The one participant whose score declined had the highest pre-IDI® DO score of all participants across the three groups, and it is possible that her pre-program score was inflated and hence declined post-program. The results of the current study would have been further strengthened by the addition of another control group that received the focused cultural interventions, but did not participate in the ISL program. 
Pre-program DO score. Another question raised during the data analysis was whether the development of intercultural competence was affected by participants' pre-program level of intercultural competence, their pre-program DO score. It has been previously reported that high school participants in the minimization stage had no change in their post-program DO score, while those in the more ethnocentric stages with lower pre-program scores had significant changes in their post-program scores (Hammer, 2005). Of the three groups in this study, the control group $(M=94.17, S D=9.77)$ and Group E2 $(M=96.80, S D=12.39)$ had similar pre-program DO scores in the range of minimization. However, the Group E1 mean pre-program DO score was significantly lower $(M=83.67, S D=10.27)$ and in the polarization stage. Results of the regression analysis indicate that there is a significant negative relationship between pre-program DO score and the change in score, suggesting that participants starting at lower pre-program scores are likely to have greater gains in score. This finding is particularly important when preparing course content activities because the implication is that specific targeted interventions may be effective for different groups based on the pre-program DO scores. Overall, the results of this study add to the previous literature and show that with intensive intentional cultural intervention activities, participants in the minimization stage can also have significant gains in their post-program DO scores.

Two other important factors need to be considered relative to this and previous work using the IDI ${ }^{\circledR}$ with SA programs: program duration and destination country.

Program duration. Many previous studies have involved longer duration SA programs, where students have been in the host country for a semester or a year and shown no change in score (Engle \& Engle, 2004; Medina-Lopez-Portillo, 2004), small increases in DO scores of 3-5 points (Anderson \& Lawton, 2011; Paige, et al., 2004; Rexeisen et al., 2008), or larger increases in DO scores of 12 points among Psychology students, with even greater increases in scores for students who had never travelled abroad (Pedersen, 2009, 2010). Among shorter duration (four to seven weeks) programs, 0-4 point increases have been reported (Anderson, Lawton, Rexeisen \& Hubbard, 2006; Jackson, 2011; Medina-Lopez-Portillo, 2004), with one study reporting a 16-point increase in DO scores after a five-week program (Jackson, 2008). The only other study of a two-week program reported a mean score increase of two points that was not significant (Pedersen, 2009). The results of this study show that larger (10-14 point) increases in DO scores are possible even after a short two-week SA program, when intentional and focused cultural intervention activities are included in course content.

Destination country. The large majority of previous work related to intercultural development via SA programs has been with programs to European nations including the United Kingdom (Anderson et al., 2006; Anderson \& Lawton, 2011; 
Pedersen, 2009, 2010; Rexeisen et al., 2008), France (Engle \& Engle, 2004), and the Netherlands (Pedersen, 2009), and large (>10 points) increases in post-program DO scores have been reported in only two studies (Pedersen, 2009, 2010). Of the studies of programs to non-European nations, Medina-Lopez-Portillo (2004) showed no change in group scores after programs to Mexico. One large study included 86 participants to a variety of countries and reported a mean increase in DO score of 4.5 points (Paige, et al., 2004). Sixty-four percent of their sample studied in Europe (Spain or France), while the remainder studied in a variety of nations including some in South America, Central America and Africa. However since the data were grouped together, the influence of destination country, if any, could not be determined. Of note are two reports of Chinese students from Hong Kong who participated in a program to Great Britain and showed mean DO score increases from 4 to 16 points (Jackson, 2008; Jackson, 2011). Substantial differences have been reported among student scores based on destination country (Hammer, 2005); however, no details regarding these differences were included. Although the effect of destination country was not addressed in this study, qualitative data included comments that reflected students being culturally challenged, such as, "I felt out of my comfort zone because I have never been the racial minority of a group" (Kim) and "I have learned how isolated and alone I can feel when I do not "look" like everyone else in the room" (Greta). It could be argued that the destination country of Zambia in this study may have played a more significant role in changes in intercultural competence compared to studies where participants went to European nations. Further research in this area is needed to identify factors that may be important in facilitating the development of intercultural competence.

\section{Developing intercultural competence in Audiology and SLP student clinicians.} This is only the second study addressing the development of intercultural competence via a SL SA program among undergraduate and graduate students in audiology and SLP, and adds to the previous work that used the Public Affairs Scale and qualitative data to demonstrate development of intercultural competence (Krishnan, et al., 2016). This study strengthens previous findings with the addition of a control group and demonstrates the effectiveness of course content that includes intentional activities on developing intercultural competence, even in the context of a short two-week SA program. With 79 educational institutions offering SA opportunities in audiology and SLP, the findings of this study can be used to develop curricula for these programs that will help students increase their intercultural competence to meet the needs of the diverse clientele they are likely to encounter in clinical practice. 


\section{References}

Amerson, R. (2012). The influence of international service-learning on transcultural self-efficacy in Baccalaureate nursing graduates and their subsequent practice. International Journal of Teaching and Learning in Higher Education, 24 (1), 6-15.

Anderson, P. H. \& Lawton, L. (2011). Intercultural Development: Study Abroad vs. On-Campus Study. Frontiers: The Interdisciplinary Journal of Study Abroad, 21, 86-108.

Anderson, P. H., Lawton, L., Rexeisen, R. J., \& Hubbard, A. C. (2006). Shortterm study abroad and intercultural sensitivity: A pilot study. International Journal of Intercultural Relations, 30(4), 457-469.

Ash, S. L., Clayton, P. H., \& Atkinson, M. P. (2005). Integrating reflection and assessment to capture and improve student learning. Michigan Journal of Community Service Learning, 49-60.

Baldwin, S. C., Buchanan, A. M., \& Rudisill, M. E. (2007). What teacher candidates learned about diversity, social justice, and themselves from service-learning experiences. Journal of Teacher Education, 58 (4), 315328.

Bennett, M. J. (1986). Toward ethnorelativism: A developmental model of intercultural sensitivity. In R. M. Paige (Ed.), Cross-cultural orientation: New conceptualizations and applications (pp. 21-70). New York: University Press of America.

Bennett, M. J. (1993). Toward ethnorelativism: A developmental model of intercultural sensitivity. In R. M. Paige (Ed.), Education for the intercultural experience (pp. 21-71). Yarmouth, ME: Intercultural Press.

Bennett, J. M. (2015). The SAGE encyclopedia of intercultural competence. SAGE Publications, Inc.

Bennett, M. J., Bennett, J. M., \& Stillings (1977). The D-I-E model. Intercultural Communication Workshop Facilitator's Manual, Portland State University, Portland, OR

Berg, M. V., Paige, R. M., \& Lou, K. H. (2012). Student Learning Abroad: What Our Students Are Learning, What They're Not, and What We Can Do About It. Stylus Publishing, LLC.

Bringle, R. G., \& Hatcher, J. A. (2010). International service learning. In R. G. Bringle, J. A. Hatcher, \& S. G. Jones, International Service Learning : Conceptual Frameworks and Research. Sterling, Virginia: Stylus Publishing, LLC.

Caffrey, R. A., Neander, W., Markle, D., \& Stewart, B. (2005). Improving the cultural competence of nursing students: Results of integrating cultural 
content in the curriculum and an international immersion experience. Journal of Nursing Education, 44 (5), 234-240.

Cokely, C. G., \& Thibodeau, L. M. (2011). Service learning in auditory rehabilitation courses: The university of Texas at Dallas. American Journal of Audiology, 20, S233-S240.

Crabtree, R. D. (2008). Theoretical foundations for international service-learning. Michigan Journal of Community Service Learning, 18-36.

Crowley, C. C., \& Baigorri, M. (2011). Effective approaches to international work: Substance and sustainability for speech-language pathology student groups. SIG 17 Perspectives on Global Issues in Communication Sciences and Related Disorders, 1(1), 27-35.

Crowley, C., \& Baigorri, M. (2012). International service that really serves. The ASHA Leader, 17(13), 30-33.

Cultural Self Awareness (2009). University of Southern Maine Muskie School of Public Service. Supervisory Practices in Child Welfare, Supervisory Training Instructor's Guide Retrieved from https://www.google.com/url?sa=t\&rct=j\&q=\&esrc=s\&source=web\&cd=2 \&ved=0ahUKEwioveC_t6jOAhUF5IMKHdgyAsoQFggiMAE\&url=http $\% 3 \mathrm{~A} \% 2 \mathrm{~F} \% 2 \mathrm{Fmuskie}$.usm.maine.edu\%2Fhelpkids\%2FSupervisionProject $\%$ FFjM1V2Act3CulturalSelfAwareness.doc\&usg=AFQjCNEsUfmkMCJ 1R6ZZqPVpy1eZG0AtVA\&cad=rja

Czerwionka, L., Artamonova, T., \& Barbosa, M. (2015). Intercultural knowledge development: Evidence from student interviews during short-term study abroad. International Journal of Intercultural Relations, 49, 80-99.

Deardorff, D. K. (2006). Identification and assessment of intercultural competence as a student outcome of internationalization. Journal of studies in international education, 10(3), 241-266.

Deeley, S. J. (2010). Service-learning: Thinking outside the box. Active Learning in Higher Education, 11 (1), 43-53.

Engle, L., \& Engle, J. (2004). Assessing Language Acquisition and Intercultural Sensitivity Development in Relation to Study Abroad Program Design. Frontiers: The interdisciplinary journal of study abroad, 10, 219-236.

Evanson, T. A., \& Zust, B. L. (2004). The meaning of participation in an international service experience among baccalaureate nursing students. International Journal of Nursing Education Scholarship, 1548-923X.

Glaser, B. G., \& Strauss, A. L. (1967). The discovery of grounded theory: Strategies for qualitative research . Chicago, IL: Aldine.

Godkin, M. A., \& Savageau, J. A. (2003). The effect of medical students' international experiences on attitudes toward serving underserved multicultural populations. FMCH Publications and Presentations, 26. 
Goldberg, L. R. (2007). Service-learning as a tool to facilitate cultural competence. Perspectives on Communication Disorders and Sciences in Culturally and Linguistically Diverse Populations, 14(1), 3-7.

Green, S. S., Comer, L., Elliott, L., \& Neubrander, J. (2011). Exploring the value of an international service-learning experience in Honduras. Nursing Education Research, 32 (5), 302-307.

Griffer, M.R. \& Perlis, S.M. (2007). Developing cultural intelligence in preservice speech-language pathologists and educators. Communication Disorders Quarterly, 29 (1), pp. 28-35.

Guo, F., Yao, M., Wang, C., Yan, W., \& Zong, X. (2015). The effects of service learning on student problem solving: The mediating role of classroom engagement. Teaching of Psychology, 1-6.

Hall, E. T (1976). Beyond Culture. New York: Anchor Press.

Hammer, M. R. (2005). Assessment of the impact of the AFS study abroad experience. New York: AFS Intercultural Programs.

Hammer, M. R. (2011). Additional cross-cultural validity testing of the Intercultural Development Inventory. International Journal of Intercultural Relations, 35(4), 474-487.

Hammer, M. R. (2015). The Developmental paradigm for intercultural competence research. International Journal of Intercultural Relations, 48, 12-13.

Hammer, M. R., Bennett, M. J., \& Wiseman, R. (2003). The Intercultural Development Inventory: A measure of intercultural sensitivity. International Journal of Intercultural Relations, 27(4), 421-443.

Jackson, J. (2008). Globalization, internationalization, and short-term stays abroad. International Journal of Intercultural Relations, 32(4), 349-358.

Jackson, J. (2009). Intercultural learning on short- term sojourns. Intercultural Education, 20(sup1), S59-S71.

Jackson, J. (2011). Host Language Proficiency, Intercultural Sensitivity, and Study Abroad. Frontiers: The Interdisciplinary Journal of Study Abroad, 21, 167188.

Kaf, W. (2012). Classroom in the clinic. The ASHA Leader, 17(3), 16-18.

Kaf, W. A., Barboa, L. S., Fisher, B. J., \& Snavely, L. A. (2011). Effect of interdisciplinary service learning experience for audiology and speechlanguage pathology students working with adults with dementia. American Journal of Audiology, 20, S241-S249.

Kaf, W. A., \& Strong, E. C. (2011). The promise of service learning in a pediatric audiology course on clinical training with the pediatric population. American Journal of Audiology, 20(2), S220-S232.

Kamkwamba, W., \& Mealer, B. (2009). The boy who harnessed the wind: Creating currents of electricity and hope. Harper Collins. 
Krishnan, L. A., Richards, K. A. R. R. \& Simspon, J. (2016). Outcomes of an International Audiology Service-Learning Study-Abroad Program. American Journal of Audiology, 25(1), 1-13.

Lincoln, Y. S., \& Guba, E. G. (1985). Naturalistic inquiry. Newbury Park, CA: Sage.

Long, T. (2014). Influence of International Service-Learning on Nursing Student. Journal of Nursing Education, 53 (8), 474-478.

Lo-Philip, S. W. Y., \& Park, J. S. Y. (2015). Imagining Self: Diversity of Bilingual Identity Among Students of an Enrichment. Journal of Language, Identity \& Education, 14(3), 191-205.

Mao, J. J., Wax, J., Barg, F. K., Margo, K., \& Walrath, D. (2007). A gain in cultural competence through an international acupuncture elective. Family Medicine-Kansas City, 39 (1), 16-18.

McBride, I., \& Belus, G. (2014, November). Humanitarian audiology: Are you making a difference? Seminar presented at the Annual Convention of the American Speech-Language-Hearing Association, Orlando, FL.

Medina-Lopez-Portillo, A. (2004). Intercultural Learning Assessment: The Link between Program Duration and the Development of Intercultural Sensitivity. Frontiers: The interdisciplinary journal of study abroad, 10, 179-199.

Miller, K. K., \& Gonzalez, A. M. (2009). Challenges and rewards associated with service-learning in international contexts: Pre-service teacher outcomes. College Student Journal, 43 (2), 56-69.

Paige, R. M., Cohen, A. D., \& Shively, R. L. (2004). Assessing the Impact of a Strategies-Based Curriculum on Language and Culture Learning Abroad. Frontiers: The Interdisciplinary Journal of Study Abroad, 10, 253-276.

Paige, RM, Jacobs-Cassutob, M, Yershovaa, YA \& DeJaegherea, J (2003). Assessing intercultural sensitivity: an empirical analysis of the Hammer and Bennett Intercultural Development Inventory, International Journal of Intercultural Relations 27: 467-486

Pakulski, L. A. (2011). Addressing qualified personnel shortages for children who are deaf or hard of hearing with an interdisciplinary service learning program. American Journal of Audiology, 20(2), S203-S219.

Patton, M. Q. (2002). Qualitative research and evaluation methods (3rd ed.). Thousand Oaks, CA: Sage.

Pedersen, P. J. (2009). Teaching towards an ethnorelative worldview through psychology study abroad. Intercultural Education, 20(sup1), S73-S86.

Pedersen, P. J. (2010). Assessing intercultural effectiveness outcomes in a yearlong study abroad program. International Journal of Intercultural Relations, 34(1), 70-80. 
Peters, K. A. (2011). Including service learning in the undergraduate communication sciences and disorders curriculum: Benefits, challenges, and strategies for success. American Journal of Audiology, 20, S181-S196.

Rexeisen, R. J., Anderson, P. H., Lawton, L., \& Hubbard, A. C. (2008). Study Abroad and Intercultural Development: A Longitudinal Study. Frontiers: The Interdisciplinary Journal of Study Abroad, 17, 1-20.

Vande Berg, M., Connor-Linton, J., \& Paige, R. M. (2009). The Georgetown consortium project: Interventions for student learning abroad. Frontiers: The Interdisciplinary Journal of Study Abroad, 18, 1-75.

Wilk, N. C. (2013). Nursing students' cultural immersion in Kenya: A case for a clinical capstone site. Journal of Nursing Education and Practice, 3 (5), 3944.

Williams, A. L., Louw, B., Scherer, N. J., Bleile, K. M., Keske-Soares, M., \& Trindade, I. E. K. (2013). Academic and clinical preparation in speechlanguage pathology and audiology: A global training consortium. Contemporary Issues in Communication Science and Disorders, 40, 40-49. 